\section{Changing the outcome measures, changing the results? The urgent need of a specific disease activity score to adult-onset Still's disease}

We read with great interest the article by Kedor $e t a l^{1}$ on the efficacy of canakinumab, an interleukin (IL) $-1 \beta$ antagonist, on patients with adult-onset Still's disease (AOSD). In this multicentre, double-blind, randomised, placebo-controlled trial, 36 patients with active joint involvement were enrolled ${ }^{1}$; this is the largest clinical trial performed on AOSD so far. Moreover, the results of this trial are of considerable interest in this field, considering the challenge of arranging prospective studies on a rare disease. Despite the improvement of many articular secondary measures, the primary outcome, the proportion of patients with a clinically relevant reduction of the articular manifestation measured by change in disease activity score $(\triangle \mathrm{DAS} 28(\mathrm{ESR})>1.2)$ at week 12 , did not achieve statistical significance. ${ }^{1}$ Apparently, this finding seems to be in contrast with the strong scientific rationale, which is behind the study, of inhibiting IL-1 $\beta$ in AOSD and with the confirmed efficacy of canakinumab reported in the juvenile counterpart of AOSD. ${ }^{23}$ As previously performed, ${ }^{45}$ the authors used the DAS28 to assess the disease activity, selecting patients with active joint involvement. Although of importance, the assessment of articular pattern could not entirely evaluate the clinical manifestations of AOSD, characterised by both systemic and articular features. In fact, during flares, patients are frequently affected by fever, which is the expression of systemic inflammation of the disease, associated with arthritis, either oligo-arthritis or bilateral symmetrical rheumatoid arthritis-like polyarthritis, with a usual migrating pattern. ${ }^{3}$ On these bases, it must be pointed out that this clinical issue reflects a big unmet need in the management of AOSD due to the lack of standardised outcome measures. In fact, an international agreement is still missing concerning the assessment of disease activity, the definition of refractory patients and the evaluation of remission. To overcome these limits, EULAR is supporting a specific working group devoted to develop and validate a disease activity score in AOSD, "Development and validation of a disease activity score in adult onset Still's Disease: the DAVID project (CLI113)". The EULAR Task Force includes experts, selected according to their field of interest and knowledge on AOSD, from a variety of European countries who are working, by a synergistic effort, to develop recommendations/ points to consider for a clinical tool measuring disease activity in AOSD and a definition of remission readily transferable into clinical practice.

Presently, the mechanism of action of some new drugs supports a strong rationale for using such therapies on AOSD ${ }^{6}$ However, the possibility to plan clinical trials is strongly limited by the lack of specifically validated outcome measures with the consequent usage of surrogate measures, derived from other diseases, which could possibly lead to false-negative results. Furthermore, a validated score measuring disease activity would also allow effective comparisons between studies, reducing the heterogeneity of the results. Such a score might also reduce healthcare costs due to decreasing a potentially unjustified use of expensive therapeutic strategies. Finally, this specifically designed disease activity score would allow to re-assess the data of previous clinical trials to fully evaluate the efficacy of study drugs on AOSD.

In conclusion, the clinical trial by Kedor et $a l^{1}$ is a further example of how the absence of validated measures could impair the expected positive results, despite the strong scientific rationale. Thus, the lack of standardised outcome measures is an urgent need to improve the management of patients with AOSD. In fact, the validated disease activity score, which will be generated by the EULAR Task Force, will allow researchers, on the one hand, to better and comprehensively investigate disease activity in these patients and, on the other, a potentially new repurposing of drugs which apparently did not show their entire usefulness in AOSD.

Piero Ruscitti, ${ }^{1}$ Tanja A Stamm $\odot,{ }^{2}$ Roberto Giacomelli $\odot{ }^{1}$

${ }^{1}$ Department of Clinical Sciences and Applied Biotechnology, University of L'Aquila, L'Aquila, Abruzzo, Italy

${ }^{2}$ Section for Outcomes Research, Center for Medical Statistics, Informatics and Intelligent System, Medical University of Vienna, Vienna, Austria

Correspondence to Dr Roberto Giacomelli, Department of Clinical Sciences and Applied Biotechnology, University of L'Aquila, L'Aquila 67100, Abruzzo, Italy; roberto.giacomelli@cc.univaq.it

Correction notice This article has been corrected since it published Online First. The author name 'Kador' has been corrected to 'Kedor' within the content.

Contributors All the authors meet all criteria for authorship in the ICMJE Recommendations since all authors made substantial contributions to the conception or design of the work, the acquisition and interpretation of data. All authors contributed to the critical review and revision of the manuscript and approved the final version. All the authors agreed to be accountable for all aspects of the work.

Funding The authors have not declared a specific grant for this research from any funding agency in the public, commercial or not-for-profit sectors.

Competing interests None declared.

Patient and public involvement Patients and/or the public were not involved in the design, or conduct, or reporting, or dissemination plans of this research.

Patient consent for publication Not required.

Provenance and peer review Not commissioned; internally peer reviewed. (C) Author(s) (or their employer(s)) 2020. No commercial re-use. See rights and permissions. Published by BMJ.

\section{Check for updates}

To cite Ruscitti P, Stamm TA, Giacomelli R. Ann Rheum Dis Epub ahead of print: [please include Day Month Year]. doi:10.1136/annrheumdis-2020-218032

Received 18 May 2020

Accepted 21 May 2020

\section{(5) Linked}

- http://dx.doi.org/10.1136/annrheumdis-2020-218143

Ann Rheum Dis 2020;0:1. doi:10.1136/annrheumdis-2020-218032

\section{ORCID iDs}

Tanja A Stamm http://orcid.org/0000-0003-3073-7284

Roberto Giacomelli http://orcid.org/0000-0003-0670-9638

\section{REFERENCES}

1 Kedor C, Listing J, Zernicke J, et al. Canakinumab for treatment of adult-onset Still's disease to achieve reduction of arthritic manifestation (consider): phase II, randomised, double-blind, placebo-controlled, multicentre, investigator-initiated trial. Ann Rheum Dis 2020;annrheumdis-2020-217155. doi:10.1136/annrheumdis-2020-217155. [Epub ahead of print: 13 May 2020].

2 Feist E, Quartier P, Fautrel B, et al. Efficacy and safety of canakinumab in patients with Still's disease: exposure-response analysis of pooled systemic juvenile idiopathic arthritis data by age groups. Clin Exp Rheumatol 2018;36:668-75.

3 Giacomelli R, Ruscitti P, Shoenfeld Y. A comprehensive review on adult onset Still's disease. J Autoimmun 2018:93:24-36.

4 Puéchal X, DeBandt M, Berthelot J-M, et al. Tocilizumab in refractory adult Still's disease. Arthritis Care Res

5 Cipriani P, Ruscitti P, Carubbi F, et al. Tocilizumab for the treatment of adult-onset Still's disease: results from a case series. Clin Rheumatol 2014;33:49-55.

6 Feist E, Mitrovic S, Fautrel B. Mechanisms, biomarkers and targets for adult-onset Still's disease. Nat Rev Rheumatol 2018;14:603-18. 